\title{
A Network Evolution Model of Credit Risk Contagion between Banks and Enterprises Based on Agent-Based Model
}

\author{
Pei Mu, ${ }^{1}$ Tingqiang Chen $\mathbb{D}^{1,2}$ Kun Pan, ${ }^{3}$ and Meng Liu $\mathbb{D}^{1}$ \\ ${ }^{1}$ School of Economics and Management, Nanjing Tech University, Nanjing 211816, China \\ ${ }^{2}$ Academy of Mathematics and Systems Science, Chinese Academy of Sciences, Beijing 100190, China \\ ${ }^{3}$ Transaction Banking Department, Bank of Nanjing, Nanjing 210008, China
}

Correspondence should be addressed to Tingqiang Chen; tingqiang88888888@163.com and Meng Liu; 15850765259@163.com

Received 6 October 2021; Accepted 28 October 2021; Published 22 November 2021

Academic Editor: Shaojian Qu

Copyright (C) 2021 Pei Mu et al. This is an open access article distributed under the Creative Commons Attribution License, which permits unrestricted use, distribution, and reproduction in any medium, provided the original work is properly cited.

\begin{abstract}
Credit risk contagion between banks and firms is one of the important triggers of financial crisis, and the credit linkage network is the way of systemic risk contagion triggered by external shocks. Considering the heterogeneity of behavioral rules, learning rules, and interaction rules, this paper constructs a bank-firm credit matching network model based on ABM (agent-based model) model and reinforcement learning algorithm to analyze the interaction behavior and credit risk network contagion mechanism. The results show that (1) macroeconomic cycles are the result of the interaction between banks and enterprises and the interaction of microentities under complex financial conditions; (2) enterprises are heterogeneous and the asset size follows a power-law distribution; (3) the greater the sensitivity of banks and enterprises to market performance, the lower the bank failure rate and enterprise default rate; and (4) shocks to the largest banks and enterprises in terms of assets and entry can all intensify the risk contagion between banks and enterprises. Therefore, the regulation of financial institutions that are "too big to fail" is not sufficient but should be a comprehensive regulation of the banking system.
\end{abstract}

\section{Introduction}

The global economic integration has deepened the close connection among economic agents, and the association between banks and enterprises, as two important support subjects of the modern economic system, has become increasingly close, forming a supernetwork with credit as the main credit connection, and the credit network of banks and enterprises can easily become the transmission channel of the risk of external shocks. Related studies have shown that bank-credit networks have the role of "financial gas pedals" and can amplify the spread of bank-enterprise credit risks. The subprime mortgage crisis and its risk contagion in the United States in 2007 are a very typical example. In China, there is a strong risk correlation between banks and enterprises in the capital chain. External shocks leading to corporate credit defaults will inevitably impact the stability of the banking system, which in turn affects the supply of credit from the banking system to the rest of the real economy, causing a vicious circle and exacerbating the credit risk contagion effect between banks and enterprises.

The existing studies on credit risk contagion between banks and enterprises mainly explore the mechanisms and laws of risk contagion between banks and enterprises from the perspectives of considering single subjects of banks and enterprises and dual subjects of banks and enterprises. First, in terms of considering only the bank subject, Giulia et al. [1] constructed an interbank lending network to study the risk contagion among banks in the presence of volatile liquid assets. Li [2] studied the impact of intersubject network structure of banks and behavioral rules of bank subjects on risk contagion. Krause and Giansante [3] concluded with the help of logit regression analysis that the topology of the credit network among bank subjects is an important factor influencing risk contagion. Lux [4] constructed an interbank credit correlation network model based on reinforcement learning algorithms, and the results showed that the interbank market has a core-periphery structure. Anand et al. 
[5] and Simone and Tedeschi [6] showed that network topology and high leverage are responsible for the formation of interbank market risk. Chen et al. [7] construct a network model of credit risk contagion in the interbank lending market based on time series and incomplete information. It investigates how the contagion effect of credit risk accumulates and spreads in the interbank market network and the evolutionary characteristics of credit risk contagion triggered by initial default of creditor banks in the interbank market. Tedeschi et al. [8] studied the impact of systemic risk as well as risk sharing on the interbank market based on the ABM model. Chen et al. [9] incorporate the average fitness for credit risk contagion, risk aversion, and the risk resistance of credit risk holders into an evolutionary network model of credit risk contagion. The impact of these factors on credit risk contagion in financial markets is investigated. However, the drawback of this type of model is that it only studies the risk evolution in the interbank market and does not consider the impact of bank default and bankruptcy on the corporate side. Secondly, in terms of considering only corporate subjects, Battiston et al. [10] introduced supply chain networks and showed that the risk of corporate default bankruptcy is transmitted from downstream to upstream firms and that the main cause is the commercial credit of the firm. Barro and Basso [11] constructed an interfirm business linkage interaction network and studied the credit risk contagion between firms. Chen and Wang [12] constructed a SIRS model of counterparty credit risk contagion. The effects, mechanisms, and evolutionary features of counterparty credit network structure and its heterogeneity, counterparty behavioral preferences, counterparty suitability, and regulatory bailout strategies on counterparty credit risk contagion are investigated. Hou et al. [13] studied the risk contagion effect between upstream and downstream firms based on a network of upstream and downstream firms. This literature mainly focuses on business linkages and risk contagion among firms, while ignoring the interaction behavior between banks and firms and the impact of corporate bankruptcy default on the banking system. Finally, considering banks and enterprises at the same time, Riccetti et al. [14]; Bargigli et al. [15]; and Giri et al. [16] studied the evolution of risk contagion in banking firms based on the financial gas pedal mechanism. Catullo et al. [17] argue that interbank risk contagion is related to the structure of the credit network of the bank and the leverage of the subject. Delli Gatti et al. [18] analyzed the characteristics of the banking firm credit network economy and showed that differences in financial positions and interactions between subjects contribute to the development of macroeconomic cycles and that the bankruptcy of one subject can generate a chain reaction of bankruptcies. He et al. [19] constructed an endogenous credit network between firms and banks and studied the distribution characteristics of simulation-generating variables such as the topology of interbank and interbank networks. Chen et al. [20] constructed a two-tier credit network model between banks and corporate counterparties by considering the impact of corporate credit defaults on their counterparties under a credit link. The mechanisms affecting the evolution of the bank-firm partnership were analyzed and the evolutionary characteristics of credit risk contagion between banks and corporate counterparties under a two-tier network. Li et al. [21] constructed a systemic risk measurement model for banking enterprises based on debt ranking and studied the contagion effect of risk between banks and enterprises from a risk feedback perspective. This literature does not analyze in depth the macroeconomic characteristics of subject interactions and the impact of uncertainty shocks on risk contagion between banks and firms.

In summary, existing studies have conducted theoretical and qualitative research on interbank risk. However, the heterogeneity and interaction of the behavioral rules of banking and corporate entities have not been investigated in depth, and how the macroeconomic characteristics of the banking and corporate system affect credit risk contagion and its evolution has not been analyzed in depth. This would make the existing research not very adequate to guide the practice of credit risk management between banks and enterprises. In view of this, in this paper, with the help of ABM (agent-based model) and reinforcement learning algorithm, considering in depth the behavioral rules, strategic choices, and interaction rules of banking and business subjects and their heterogeneity, construct a bank-enterprise credit matching network model and study in depth the mechanism of macroeconomic characteristics between banks and enterprises and their network structure on credit risk contagion between banks and enterprises. The research in this paper will be helpful to grasp the interaction mechanism of credit risk contagion among subjects at the microlevel and will also be helpful to control the evolution law of credit risk contagion among banks and enterprises at the macrolevel, which is of great significance to prevent systemic financial risks.

\section{ABM Model of Bank-Enterprise Endogenous Credit Matching Network}

The endogenous credit network contains corporate subjects and bank subjects, and the credit association between banks and enterprises forms the edge of the credit network. Companies invest in the production of perishable products, and they finance production with their own assets and loans provided by banks. At the same time, both banks and firms choose their respective target levers to maximize profits through enhanced learning mechanisms. It is assumed that the credit agreement has only two periods and that both consumer and credit markets are considered, but with a greater focus on the banking and corporate credit market, simplifying the consumer market.

\subsection{Enterprise Subject Behavior Model}

2.1.1. Enterprise Output. Considering the enterprise system as a discrete evolutionary system, in the period each enterprise produces using its own capital $\left(K_{i, t}\right)$. Under the premise of full capacity utilization, the firm produces based on the ideal output of capital as shown in the following equation: 


$$
Y_{i, t}=\rho K_{i, t},
$$

where $Y_{i, t}$ is the output of the firm $i=1, \ldots, M(M=500)$ in the time period $t=1, \ldots, T(T=500)$ and $\rho$ is the coefficient of production technology of capital, $0<\rho<1$.

According to the balance sheet constancy equation, the capital of the enterprise is shown in the following equation:

$$
K_{i, t}=L_{i, t}+\phi L_{i, t-1}+E_{i, t} .
$$

Capital is equal to the sum of net equity $\left(E_{i, t}\right)$ and loans. Firm loans include loans assumed in time $t\left(L_{i, t}\right)$ and the part of the loans borrowed at time $t-1$ that is repaid at time $t\left(\phi L_{i, t-1}\right)$, where $\phi(0<\phi<1)$ represents the repayment ratio of the previous loan in the current period. Since the enterprise can obtain loans from multiple banks, the final loan amount of the enterprise is equal to the sum of the loans obtained from all the banks, namely:

$$
L_{i, t}=\sum_{z} L_{i, z, t} .
$$

2.1.2. Enterprise Loan Demand and Decision. It is assumed that at the beginning of the period each firm determines a target leverage level $\beta_{i, t}$ of its own, which is equal to the ratio of the firm's loans to its own net equity. Loans include the current period's loan demand and the previous period's loans that need to be repaid, so that there are

$$
\beta_{i, t}=\frac{\left(L_{i, t}^{d}+\phi L_{i, t-1}\right)}{E_{i, t}} .
$$

According to formula (4), the current loan demand of enterprises can be obtained as follows:

$$
L_{i, t}^{d}=\beta_{i, t} E_{i, t}-\phi L_{i, t-1} .
$$

It is assumed that the target leverage of an enterprise is determined by the leverage strategy $\left(\eta_{i, t}\right)$ chosen in each period, $\beta_{i, t}=1 / \eta_{i, t}-1$. Because loans are risky, companies will consider their own bankruptcy and risk aversion. To incorporate these factors into the model, a risk appetite coefficient is given $\psi_{f} \in[0,+\infty)$, where $\psi_{f}=1$ is risk neutral. Therefore, the impact of an enterprise's risk appetite on its actual target leverage ratio is

$$
\beta_{i, t}=\psi_{f}\left(\frac{1}{\eta_{i, t}}-1\right) .
$$

Combining formula (5) and formula (6), the loan demand of enterprises is updated as follows:

$$
L_{i, t}^{d}=\psi_{f} \frac{E_{i, t}}{\eta_{i, t}}-\psi_{f} E_{i, t}-\phi L_{i, t-1} .
$$

Enterprises use reinforcement learning algorithms to select their leverage strategies $\left(\eta_{i, t}\right)$ from a set of limited strategy sets $G$. The lower the $\eta_{i, t}$, the higher the target leverage $\left(\beta_{i, t}\right)$ and, thus, the higher the risk taken by the firm.
The enterprise loan interest rate $\left(r_{i, t}\right)$ is the function of the enterprise's current target leverage ratio and the benchmark deposit interest rate $(r)$ set by the bank:

$$
r_{i, t}=r \exp \left(\alpha \beta_{i, t}\right) \text {. }
$$

In formula (8), the parameter $\alpha$ is the sensitivity of the bank to the corporate target leverage ratio, which reflects the sensitivity of the bank to the corporate total debt.

2.1.3. Marginal Revenue and Net Value of the Enterprise. Assuming that the interest rate paid by the enterprise and the bank on their respective equity is equal to the prime rate, the change in the profit of the business entity is affected by sales revenue $\left(u_{i, t} Y_{i, t}\right)$, dividend payments $\left(r E_{i, t}\right)$, interest payments on bank loans, and other fixed costs $\left(F_{f}\right)$. Therefore, the marginal income of the enterprise $i$ is

$$
\pi_{i, t}=u_{i, t} Y_{i, t}-r E_{i, t}-r_{i, t} L_{i, t}-\phi r_{i, t} L_{i, t-1}-F_{f},
$$

where $u_{i, t}$ is the actual price of a unit product of an enterprise, including the marginal cost price $m$ related to loans and a random component $\left(\varepsilon_{i, t}\right)$, which represents the unpredictable fluctuation of demand in the consumer market. Therefore, every business wants $\varepsilon_{i, t}$ the expected value to be zero and meets

$$
\begin{aligned}
u_{i, t} & =m+\varepsilon_{i, t}, \\
\varepsilon_{i, t} & \sim N(0, \sigma) .
\end{aligned}
$$

Proposition 1. If the marginal cost pricing of any enterprise satisfies $m>r_{\max } / \rho$, the enterprise subject can operate well without the fluctuation of consumer market demand.

Proof. Only considering that enterprises use loans for production, so as long as the price is higher than the variable cost, enterprises can obtain marginal revenue to cover the fixed cost, and the surplus is profit:

$$
m \rho\left(L_{i, t}+\phi L_{i, t-1}\right)>r_{i, t} L_{i, t}+\phi r_{i, t} L_{i, t-1} .
$$

Formula (11) can be simplified as follows:

$$
m>\frac{r_{i, t}}{\rho},
$$

$r_{i, t}$ is different between enterprises. Therefore, as long as $m>r_{\max } / \rho$ is used, the larger the marginal cost price $m$ is, the more the profits the enterprise will make and the better its operation will be. Proposition 1 is proved.

As mentioned above, from Proposition 1, assuming that $\delta$ is a real number greater than zero, then the marginal cost price $m$ of an enterprise is

$$
m=r_{\max } / \rho+\delta, \delta>0 .
$$

Assuming that part of the profits is not accumulated $\left(\tau \pi_{i, t}, 0<\tau<1\right)$ for enterprises, the net equity of the enterprise $i$ is accumulated as follows: 


$$
\begin{cases}E_{i, t}=E_{i, t-1}+(1-\tau) \pi_{i, t}, & \pi_{i, t}>0, \\ E_{i, t}=E_{i, t-1}+\pi_{i, t}, & \pi_{i, t} \leq 0 .\end{cases}
$$

2.2. Behavior Model of Banks. According to credit rating in reality, banks tend to learn repeatedly to update credit strategy based on corporate loan repayments and their own assets and liabilities. So the mechanism for banks' behavior is divided into three stages.

The first stage is to update the level of credit supply. The bank entity provides loans $\left(L_{z, t}\right)$ through its own equity $\left(E_{z, t}\right)$ and deposits $\left(D_{z, t}\right)$, and the bank entity has a balance sheet of $L_{z, t}=D_{z, t}+E_{z, t}, z=1, \ldots, N,(N=50)$. Similarly, the bank uses the learning algorithm to select $\eta_{z, t} \in G$ to establish the level of credit supply. The bank's potential credit supply level is reduced by the total amount of loans outstanding to the firm $i$, as shown in the following equation:

$$
L_{z, t}^{s}=\frac{E_{z, t}}{\eta_{z, t}}-\sum_{I_{z, t-1}} \phi L_{i, z, t-1} .
$$

For firms, a riskier leverage strategy corresponds to a lower level of $\eta_{i, t}$. The smaller $\eta_{i, t}$ is, the more loans that banks need to provide, which indirectly makes them more dependent on external funds. Thus, the lower $\eta_{i, t}$ increases the leverage of the bank, increasing the risk of the bank entity.

The second stage is to update the marginal revenue of the banking entity. The marginal revenue consists of the sum of the interest on the borrower's loan for two periods, the bad debt of the associated enterprise in bankruptcy for two periods $(B D)$, interest payments on deposits, dividend payments, and fixed costs $\left(F_{b}\right)$. Therefore, the marginal revenue of the banking entity is

$$
\begin{aligned}
\pi_{z, t}= & \sum_{I_{z, t-1}} r_{i, z, t-1} L_{i, z, t-1}+\sum_{I_{z, t}} r_{i, z, t} L_{i, z, t}-B D_{t-1} \\
& -B D_{t}-r\left(E_{z, t}+D_{z, t}\right)-F_{b} .
\end{aligned}
$$

The third stage is to update the net value of the bank. Assuming that part of the profits is not accumulated $\left(\tau \pi_{z, t}, 0<\tau<1\right)$, the net value of banks is accumulated according to the following formula:

$$
\begin{cases}E_{z, t}=E_{z, t-1}+(1-\tau) \pi_{z, t}, & \pi_{z, t}>0, \\ E_{z, t}=E_{z, t-1}+\pi_{z, t}, & \pi_{z, t} \leq 0 .\end{cases}
$$

2.3. Bank-Enterprise Credit Matching Mechanism. Firms and banks determine their respective loan demand and supply at the beginning of the period. On the one hand, each firm can borrow from different banks until its own loan demand is met. On the other hand, each bank lends to firms with demand until the supply of loans is exhausted.

Because banks can reject loan applications from firms considered too risky, the probability $\left(p_{R}\right)$ of accepting a loan demand for firm $i$ is related to the firm's current choice of leverage strategy, namely:

$$
p_{R}=\frac{1}{e^{\xi\left(1-\eta_{i, t}\right)}},
$$

where $\xi$ is a constant.

Proposition 2. The higher the target leverage ratio a firm chooses, the lower the probability that the firm's loan demand will be accepted by the bank.

Proof. Formula (18) derivates the leverage strategy of the enterprise as follows:

$$
\frac{d p_{R}}{d \eta}=\frac{\xi}{e^{\xi(1-\eta)}}
$$

From equation (19), we can know that $d p_{R} / d \eta>0$. Therefore, the probability that the enterprise loan is accepted by the bank is an increasing function of the enterprise's choice of strategy.

According to $\beta_{i, t}=1 / \eta_{i, t}-1$, leverage strategy and leverage ratio are inverse functions of each other. Therefore, the higher the corporate target leverage ratio, the lower the probability that the corporate loan demand will be accepted by the bank. Proposition 3 is proved.

Proposition 3. This shows the sensitivity of banks to corporate leverage. In addition to the requirement for banks to hold deposit reserves under Basel III, setting a maximum corporate leverage ratio acceptable to banks can prevent the spread of systemic risk in banks and enterprises.

2.4. Bank and Enterprise Strategy Selection. Banks and firms choose the strategies $\left(\eta_{z, t}\right.$ and $\left.\eta_{i, t}\right)$ to determine their target leverage levels at the beginning of the period. The strategies $\eta_{z, t}$ and $\eta_{i, t}$ are selected in a finite countable set $G$. The selection mechanism is a simple generalization of the learning algorithm of Tesfatsion [22]. At the beginning of the period, banks and firms measure the effectiveness of each leverage strategy based on the profits of the previous period, namely:

$$
q\left(\eta_{s}\right)_{i, t}=(1-\chi) q\left(\eta_{s}\right)_{i, t-1}+\pi_{i, s, t-1}
$$

where $\eta_{s}=\left(\eta_{z, t}, \eta_{i, t}\right)$. Banks and firms evaluate each leverage strategy against $q\left(\eta_{s}\right)_{i, t}$ and update it at the beginning of the period when the strategy is selected. The parameter $\chi$ value is chosen to limit the impact of past value of strategy effectiveness to allow agents to rapidly adapt to the changing conditions of the economic system, $0<\chi<1$. Therefore, the higher the profit associated with a strategy, the higher the effectiveness of that strategy and the higher the probability of choosing that strategy. The effectiveness of the strategy choice at the beginning of the period is reduced by $\zeta(0<\zeta<1)$, namely: $q\left(\eta_{s}\right)_{i, t-1}=(1-\zeta) q\left(\eta_{s}\right)_{i, t-1}$.

Since business loans are divided into two periods, companies must consider their own past debts. If a company's business mismanagement in the previous period causes its own net asset value to decline and it appears that its own leverage level is higher than the specified maximum 
leverage level, then the company will not apply for a loan and the bank will not provide credit to the company. Thus, once the effectiveness of each strategy is evaluated, each strategy corresponds to a probability value that determines how likely the subject is to choose that strategy. The probability of each strategy $\left(\eta_{s}\right)$ is given by $p\left(\eta_{s}\right)_{i, t}$ :

$$
\begin{aligned}
X_{i, s, t} & =\left(\frac{q\left(\eta_{s}\right)_{i, t}}{c}\right)^{\nu}, \\
p\left(\eta_{s}\right)_{i, t} & =\frac{e^{X_{i, s, t}}}{\sum_{G_{a}} e^{X_{a, t}}},
\end{aligned}
$$

where $X_{i, s, t}$ is the relative strength of the firm's $i$ selection strategy $s$ in period $t$, depending on the effectiveness of the strategy, and $c$ and $v$ are model parameters. The index value of each strategy strength $\left(X_{i, s, t}\right)$ is used to calculate its probability of being selected for that strategy $p\left(\eta_{s}\right)_{i, t}$.

However, in the basic learning mechanism, it is not considered that different strategies generate different profits in each period, and it may bring positive or negative returns. Therefore, using the improved reinforcement learning algorithm of Ermanno Catullo et al. [17], subjects are assumed to correct their strategy choices according to the standard deviation of profits $\left(\sigma_{\pi}\right)$ over multiple periods for a given strategy. The standard deviation of profit is calculated based on the profit value of each strategy for the most recent multiple periods. That is, strategy effectiveness $v\left(\eta_{s}\right)_{i, t}$ is updated using profit fluctuations.

$$
v\left(\eta_{s}\right)_{i, t}=(1-\chi) v\left(\eta_{s}\right)_{i, t-1}+\sigma_{\pi} .
$$

From the above $v\left(\eta_{s}\right)_{i, t-1}=(1-\zeta) v\left(\eta_{s}\right)_{i, t-1}$, the probability of each strategy being selected is

$$
\begin{aligned}
X_{i, s, t} & =\left(\frac{q\left(\eta_{s}\right)_{i, t}}{c+\omega v\left(\eta_{s}\right)_{i, t}}\right)^{v}, \\
p_{\sigma}\left(\eta_{s}\right)_{i, t} & =\frac{e^{X_{i, s, t}}}{\sum_{G_{a}} e^{X_{a, t}}},
\end{aligned}
$$

where the probability $p_{\sigma}\left(\eta_{s}\right)$ describes the magnitude of the likelihood of a particular strategy choice. The parameter $\omega$ indicates the sensitivity of banks and firms to past market performance. $\omega v\left(\eta_{s}\right)_{i, t}$ reduces the probability that strategies with high profit volatility will be selected.

Proposition 4. The greater the sensitivity of banks and firms to past market performance, the lower the bank failure rate and the lower the default rate of firms.

Proof: The first-order derivative of the sensitivity of equation (23) to the past performance of the market is

$$
\frac{d X}{d \omega}=-v\left(\frac{q\left(\eta_{s}\right)}{c+\omega \nu\left(\eta_{s}\right)}\right)^{v-1} \frac{q\left(\eta_{s}\right) v\left(\eta_{s}\right)}{\left(c+\omega \nu\left(\eta_{s}\right)\right)^{2}} .
$$

As shown in equation (25), the intensity of strategy selection decreases as the sensitivity of banks and firms to past market performance $\omega$ rises. That is, in the reinforcement learning algorithm mechanism, the probability of each policy being selected will be fairer. Combined with the simulation results in Figure 1, as the sensitivity of banks and firms to past market performance rises, the bank failure rate and firm default rate both decrease, and the bank failure rate and firm default rate decrease. Proposition 4 is proved.

\section{Computational Simulation of Credit Risk Contagion in Banking Enterprises}

Given the complexity of the model in this paper and the unavailability of real data, numerical computational simulation analysis with the help of MATLAB becomes relatively the most effective test method. According to the related research results of Riccetti et al. [14], Catullo et al. [17], and other scholars, the number of bank nodes in the banking system is assumed to be 50 and the number of enterprise nodes is 500 , and the simulation is simulated for 500 cycles. At the beginning of the calculation simulation, the net value of each firm is set to 1 and the net value of each bank is set to 3 . When the banking firm becomes insolvent, it will be replaced by a new banking firm, with the new bank and the firm's initial ownership interest being random numbers in the interval $(0,3)$ and $(0,1)$, respectively. Other important parameters are set as shown in Table 1. Drawing on the parameters in related work by Catullo et al. [17], in this paper we set the set of strategies to $G=\{1.0,1 / 1.5,1 / 2,1 / 2.5,1 / 3,1 / 3.5,1 / 4,1 / 4.5,1 / 5,1 / 5.5$, $1 / 6,1 / 6.5,1 / 7,1 / 7.5,1 / 8\}$.

3.1. Emergence Characteristics of Bank-Enterprise System. Based on the parameter values in Table 1, each simulation run was calculated for 500 periods. The first 250 periods of each simulation are omitted because the model needs to be initialized. Meanwhile, for the reason of stability of simulation results, all the results of this paper are the average of 100 Monte Carlo simulations of the corresponding variables. Figure 2 illustrates the time series evolution of total firm output. As can be seen from Figure 1, the fluctuations in total firm output are irregular, with amplitudes and periods varying considerably from subcycle to subcycle. This is due to the fact that, in a complex adaptive system, each firm's decisions and its own assets vary from period to period, resulting in different total outputs. Figure 3 illustrates the time series evolution of the number of credits in the banking and corporate credit network. As can be seen from Figure 3, the overall fluctuations in the volume of credit are largely consistent with the overall fluctuations in total firm output. From equation (1), it can be seen that the firm's own assets and the amount of credit determine the firm's output.

Combining Figures 2 and 3, we can obtain that, during the expansionary phase of the economy, banks provide more credit and firms' output increases, but they also face the risk of high debt crisis. The high debt crisis backfired on banks' earnings; as the amount of credit provided by banks became less, the total output of firms decreased, causing the economy recession. 


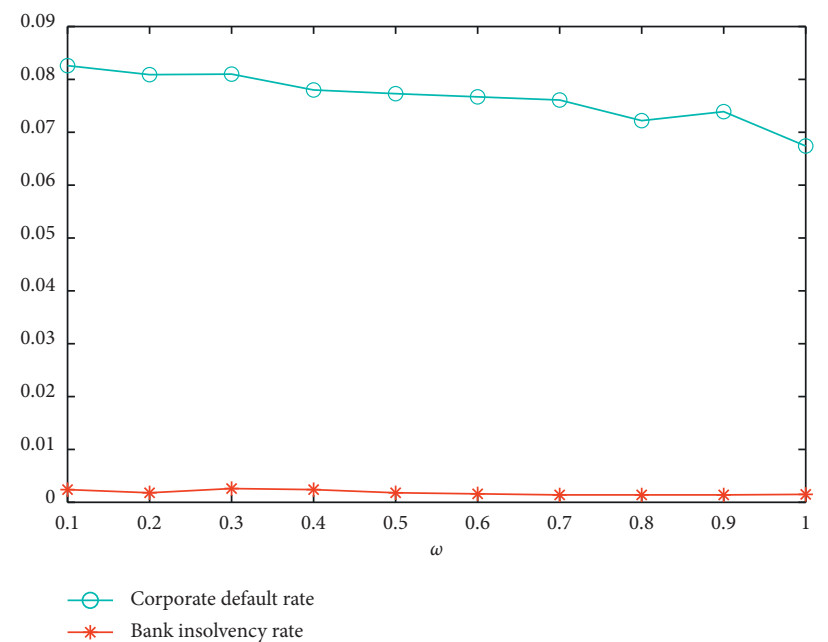

FIGURE 1: Evolutionary characteristics of corporate default rate and bank insolvency rate with sensitivity.

TABLE 1: Model baseline parameter values.

\begin{tabular}{lcc}
\hline Parameter & Parameter meaning & Base case \\
\hline$i=1, \ldots, M$ & Number of firm agents & 500 \\
$z=1, \ldots, N$ & Number of bank agents & 50 \\
$t=1, \ldots, T$ & Number of model periods & 500 \\
$E_{i}$ & Initial net value of the firm & 1 \\
$E_{z}$ & Initial net value of the bank & 3 \\
$\rho$ & Firm capital production factor & 0.1 \\
$\phi$ & Firm loan repayment ratio \\
$r$ & Base rate \\
$\psi_{f}$ & Risk appetite factor of firm agents \\
$\alpha$ & Sensitivity of banks to corporate target leverage & 0.5 \\
$\sigma$ & The variance \\
$\delta$ & Real numbers \\
$\tau$ & Profit share that is not accumulated \\
$F$ & Fixed costs \\
$\xi$ & Constants & 0.1 \\
$\chi$ & Validity of past values of strategies \\
$\zeta$ & The "forgetting" parameter \\
$c$ & The model of constant \\
$v$ & The model of constant & 1.300 \\
\hline
\end{tabular}

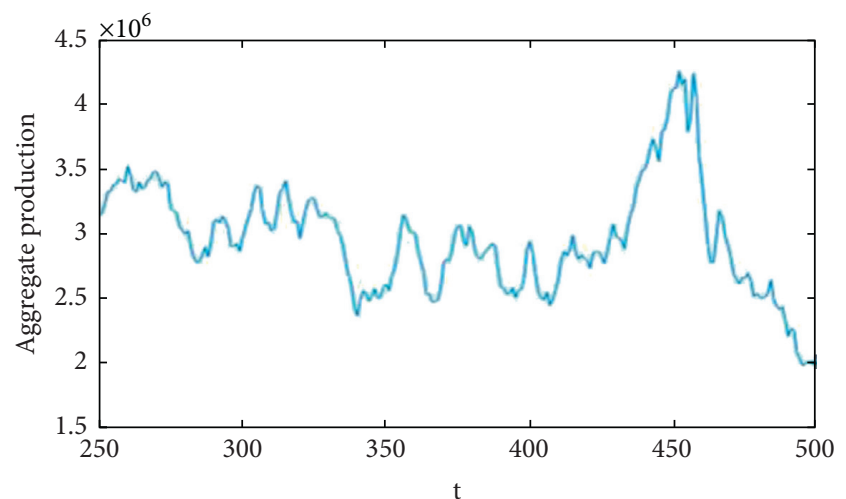

FIGURE 2: Time series evolution of aggregate production.

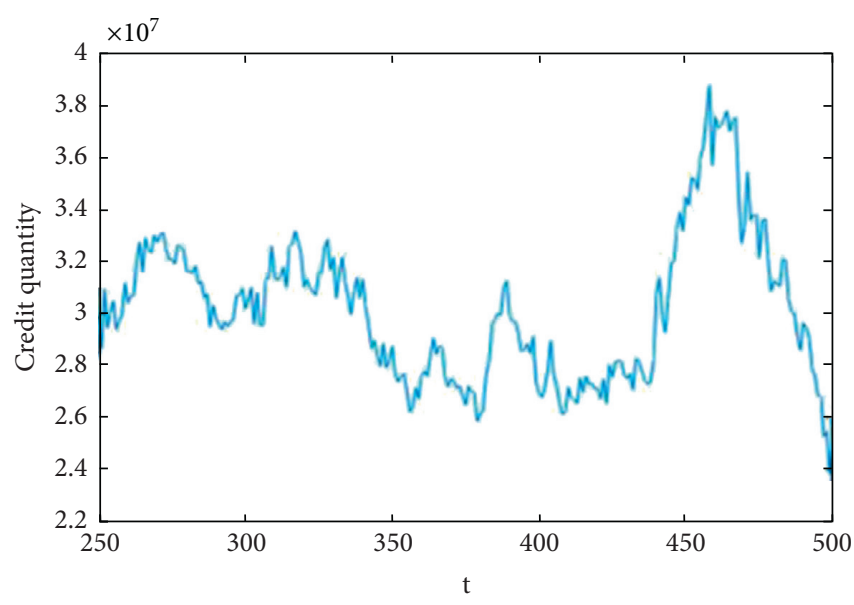

FIGURE 3: Time series evolution of credit quantity. 
Figure 4 illustrates the strong heterogeneity of the 500 firms as the simulation progresses under the same initial conditions and the power-law distribution of firm asset size. This is due to the fact that, in each period, each firm is subject to market uncertainties resulting in different prices for its products, and therefore each firm has a different rate of net asset accumulation.

Figure 5 shows that the bank node degree distribution has a double power-law characteristic. A few banks have a node degree greater than 30 , which indicates a core-edge structure of the banking enterprise credit network. This also means that only a few bank nodes in the bank-enterprise credit network are at the center of the network, have a high level of activity, and form an intensive loan association with the enterprise. In general, financially sound banks are better able to provide credit and thus increase their market share, so they can attract more connections. As a result, both the corporate and banking sectors become polarized and the degree distribution becomes asymmetric. This polarization increases the vulnerability of the banking and corporate credit network to shocks, due to the fact that defaults by highly connected institutions, even if relatively rare events, can create risk contagion between banks and enterprises. And the possibility of this occurrence depends on the network structure.

As can be seen in Figure 6, bad debts are always present in the banking and corporate credit network. The bankruptcy of a single firm has a significant impact on the net asset value of the banks, potentially creating the tide of bankruptcy. The scale depends on the amount of bad debts. At the same time, the banks and enterprises network are weak robust and the banks have absorbed those bad debts, so there will not be a massive bankruptcy. In addition, the distribution of the growth rate of total firm output is far from Gaussian and is characterized by positive and negative fluctuations around zero (Figure 7).

Based on the above calculation and analysis, this paper further analyzes the credit matching mechanism between banks and enterprises. As can be seen from Figure 8, the higher the target leverage of the firm, the higher the interest rate on the loan and the lower the probability that the firm's loan demand will be accepted by the bank. In other words, highly leveraged companies face higher interest rates on loans, more debt, and more difficult loan financing, with some potential for bankruptcy. Therefore, real-time regulation of highly leveraged companies is essential.

The above computational simulations show how the presence of uncertainties affect the financial position of firms and banks. Financial vulnerability can amplify the impact of these uncertainties in the banking and corporate credit network.

\subsection{Impact of Uncertainty Shocks on Risk Contagion between Banks and Enterprises}

3.2.1. Impact of Shocks to Asset-Largest Banks on Risk Contagion between Banks and Enterprises. With the development of financial innovation and economic

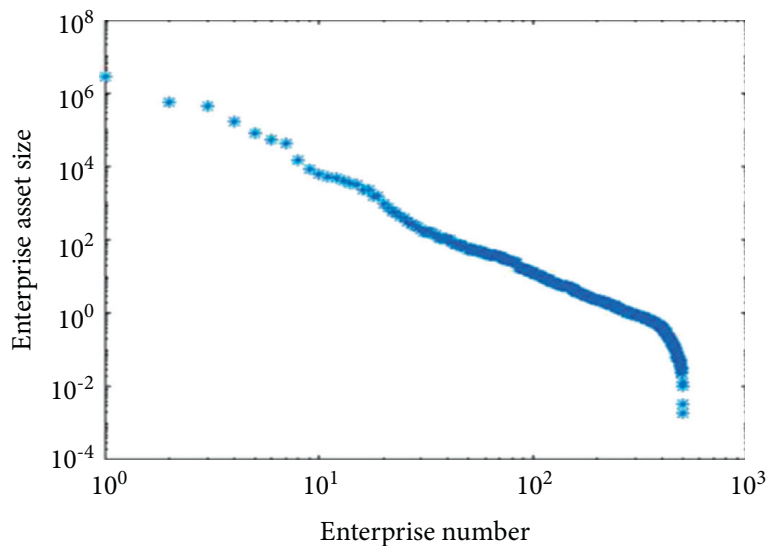

Figure 4: Asset size distribution of firms (double logarithmic coordinates).

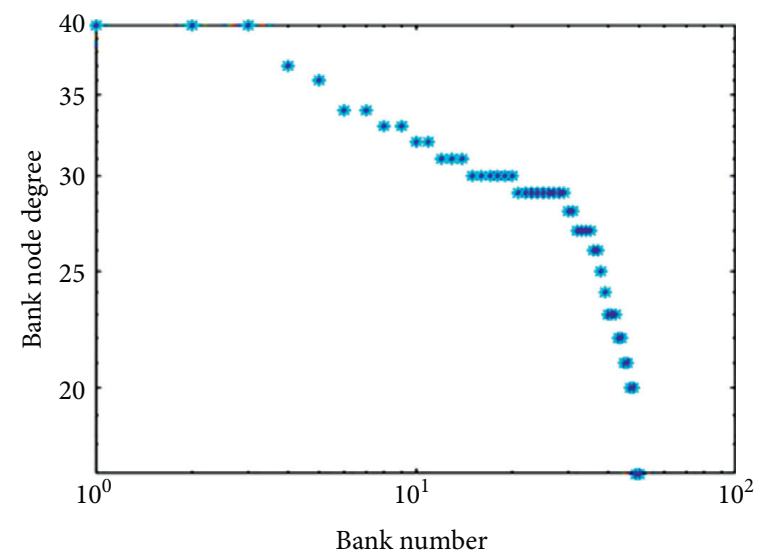

FIgURE 5: Degree distribution of bank nodes (double logarithmic coordinates).

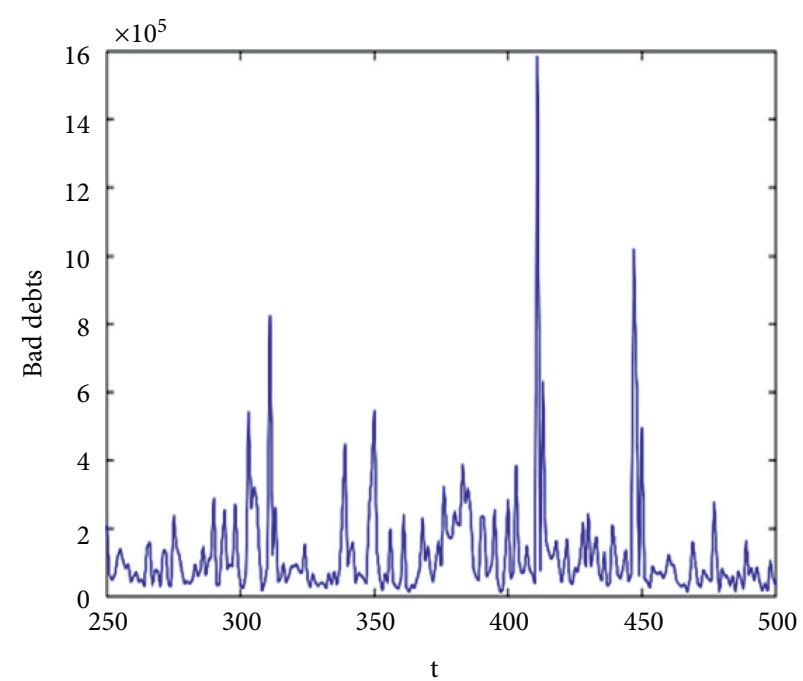

Figure 6: Time series evolution of the number of bad debts.

globalization, an increasing number of large-scale financial institutions have emerged. Its impact will inevitably bring systemic risk to the entire banking system and even the 


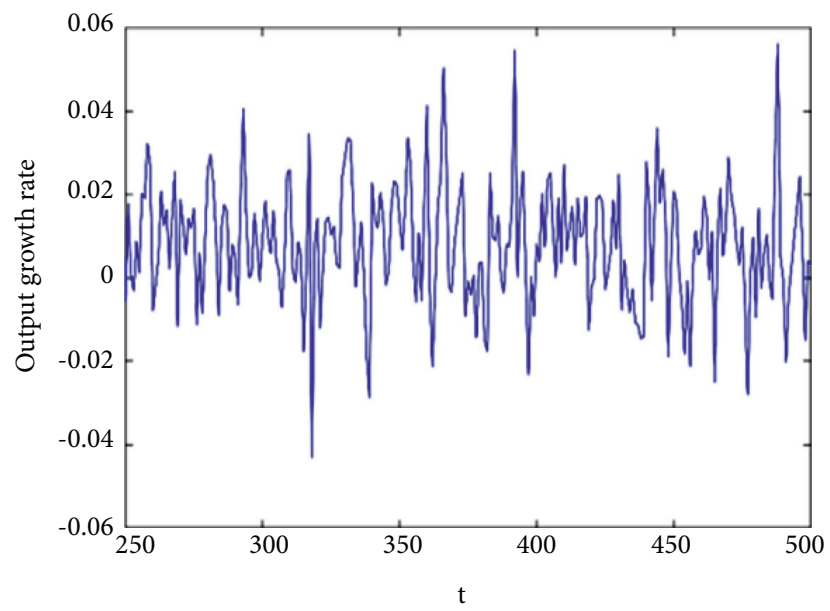

FIGURE 7: Time series evolution of output growth rate.
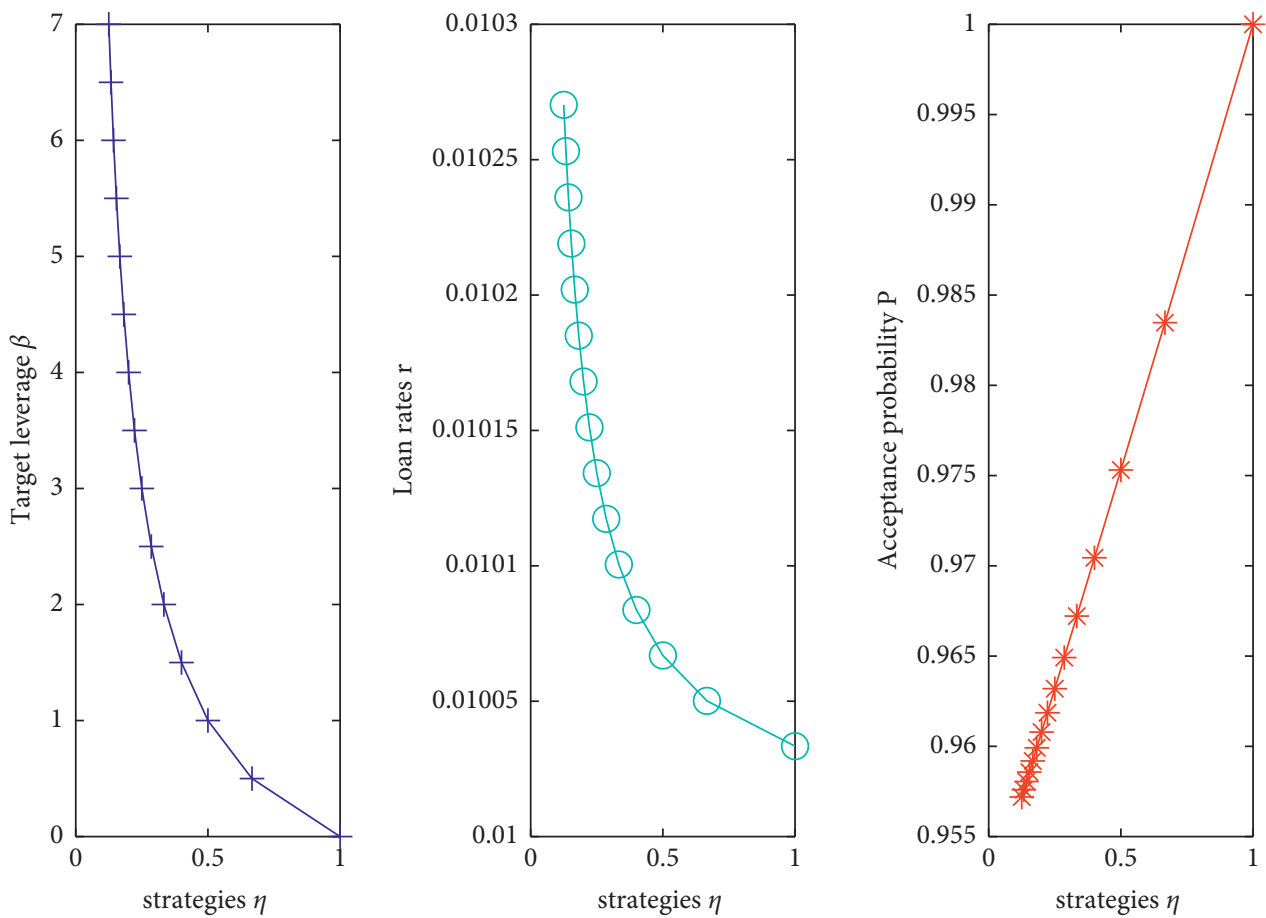

FIGURE 8: Evolutionary characteristics of target leverage, loan interest, and acceptance probability with strategy.

entire economic system [23]. Since the subprime crisis in 2007, regulators have adopted various policies to ensure the safety and stability of large financial institutions. Therefore, this section analyzes the impact of external risk shocks to the largest asset banks on the entire banking system (as shown in Figure 9). It is assumed that the external risk shock of the bank with the largest assets is, respectively, implemented in $t=250, t=300, t=350, t=400, t=450$, and $t=500$ periods. Figure 9 illustrates the evolutionary path of the corporate default rate, bank insolvency rate, and the number of bad loans following external shocks to asset-max banks in each period, where the solid asterisk line represents the evolutionary characteristics of the corporate default rate, bank insolvency rate, and the number of bank bad loans after a shock to the largest asset banks. The solid circle line represents the evolutionary characteristics of the default rate of banking firms and the number of bad loans of banks before the shock. As can be seen in Figure 9, the external shocks to the most capitalized banks exacerbate the degree of risk contagion among banking firms. Moreover, for the whole bank and enterprise network, the external shock of the bank with the largest assets leads to a significant increase in the number of bad debts in each period, which intensifies the systemic risk of banks and enterprises. Based on this, the reality is that regulators should strengthen the supervision of banks with large assets in order to prevent the contagion of banking risks caused by their bankruptcy. 

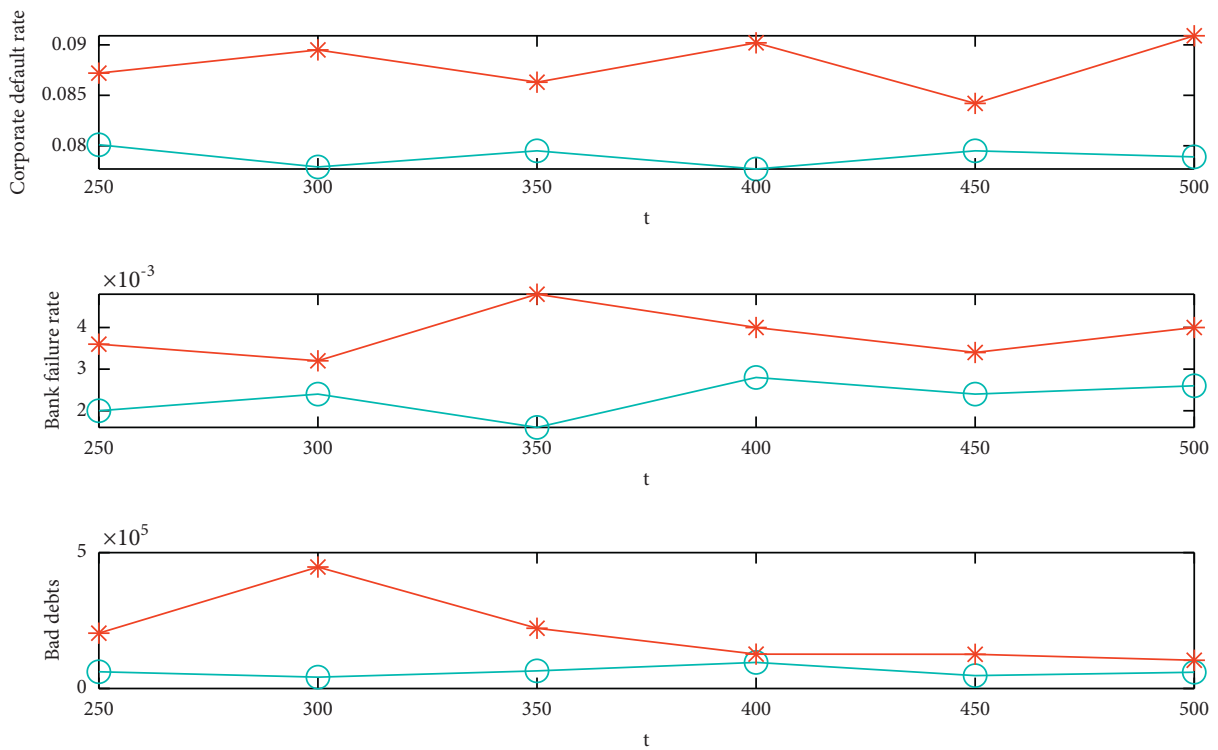

FIgURE 9: Evolution of risk contagion between banks and enterprises due to shocks to the largest banking entities in terms of assets.

3.2.2. Impact of Shocks on Interbank Risk Contagion for the Largest Banks in the Entry Degree. In fact, the regulation and protection of "too big to fail" banks are not enough to eliminate the risk of contagion from banking enterprises. Battiston et al. [24] point out that when regulating "too big to fail" institutions, "too connected to fail" institutions should also be included. Miranda and Tabak [25] show that the largest degree of entry, the default of financial institutions that borrow from a large number of other economic agents, will trigger large-scale negative effects. Catullo et al. [17] emphasize the importance of shifting policy attention from "too big to fail" to "too relevant to fail." Based on previous studies, this section will focus on the risk contagion between banks and firms due to shocks to the largest banks in the entry degree. It is assumed that the external risk shock of the bank with the largest exposure is, respectively, implemented in $t=250, t=300, t=350, t=400, t=450$, and $t=500$ periods. Figure 10 illustrates the evolution of the corporate default rate, bank insolvency rate, and the number of bad loans following external shocks to the largest banking entities in each period of entry, where the solid asterisk line represents the evolutionary path of the corresponding variable after a shock to the bank with the largest entry degree. The solid circle line represents the evolutionary path of each variable before the shock. From Figure 10, it can be seen that the external shock to the largest bank in the entry degree leads to a significantly higher bank insolvency rate per period than the bank insolvency rate per period before the shock. Firms' default rate per period is relatively higher than the preshock firm default rate per period. But compared with before the shock, the number of bad debts has not significantly increased. As a result, the impact on the largest banks has exacerbated the risk contagion between banks and enterprises. It also reaffirms that it is not enough to regulate "too big to fail" financial institutions without going bankrupt. Attention should also be shifted to the regulation of "too connected to fail" financial institutions. Financial institutions with large assets and large entry degrees should be monitored in a focused manner to prevent the domino effect resulting from their bankruptcy.

\subsubsection{Impact of Consumer Market Shocks on Risk Contagion} between Banks and Enterprises. This section will focus on exploring the impact of consumer market shocks on risk contagion between banks and firms. Assume that consumer market shocks are implemented in periods $t=250, t=300$, $t=350, t=400, t=450$, and $t=500$. Figure 11 illustrates the evolutionary path of corporate default rates, bank insolvency rates, and the number of bad bank loans following shocks to consumer markets in each period, where the solid asterisk line represents the evolutionary path of the corresponding variable after a shock to the consumer market. The solid circle line represents the evolutionary path of each variable before the shock. As can be seen from Figure 11, the default rate of firms per period is significantly higher than the default rate of firms per period before the shock, which increases exponentially. However, the bank failure rate is slightly higher than the preshock bank failure rate. For the whole network of banks and enterprises, the impact of the consumer market leads to a significant increase in the number of bad debts in each period, which intensifies the systemic risk of banks and enterprises. That is, consumer market shocks have severely exacerbated corporate default bankruptcies. Significant increase in the number of bad debts thus affects banks' earnings. However, most of the bad loans were absorbed by the banks due to the accumulation of precapitalization of the banks, without creating a large-scale bank failure. Therefore, banks act as financial stabilizers in the banking and enterprises credit network. This is consistent with the findings of Braun and Larrain [26], Raddatz [27], and Ashraf [28]. 

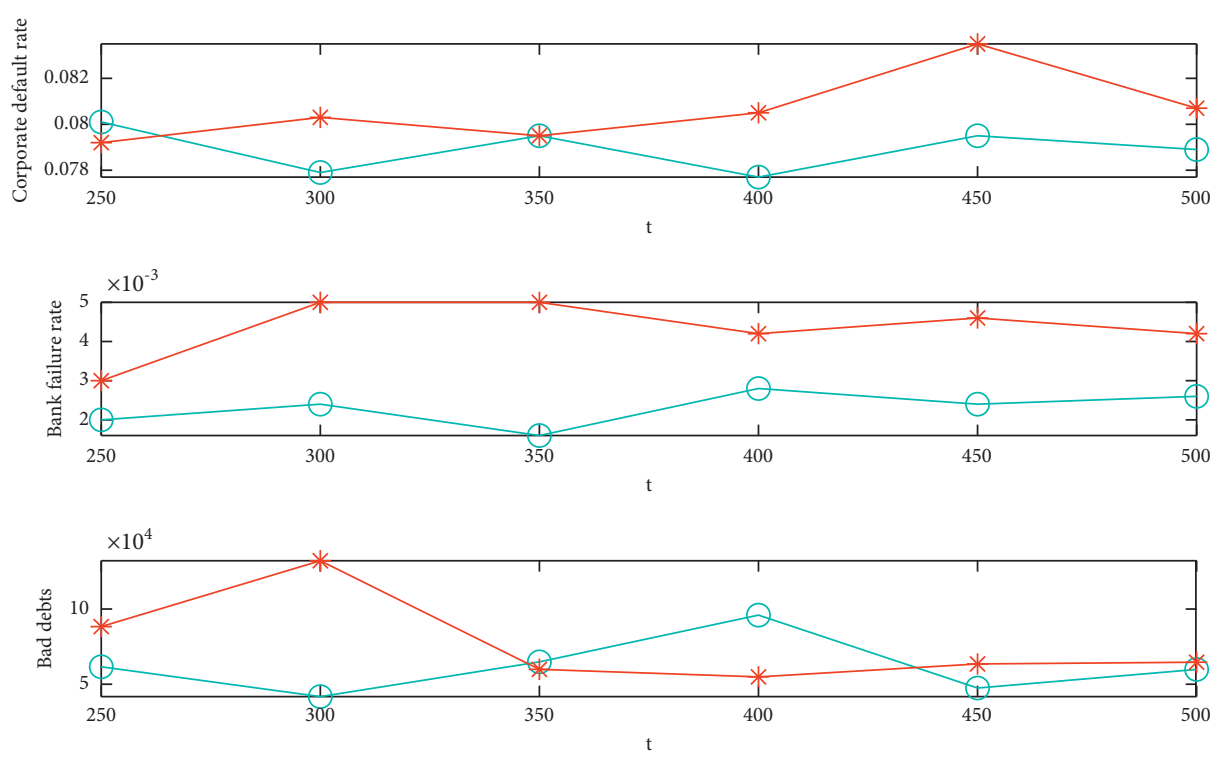

FIGURE 10: Evolution of risk contagion between the largest banks in terms of entry shocks and banking firms.
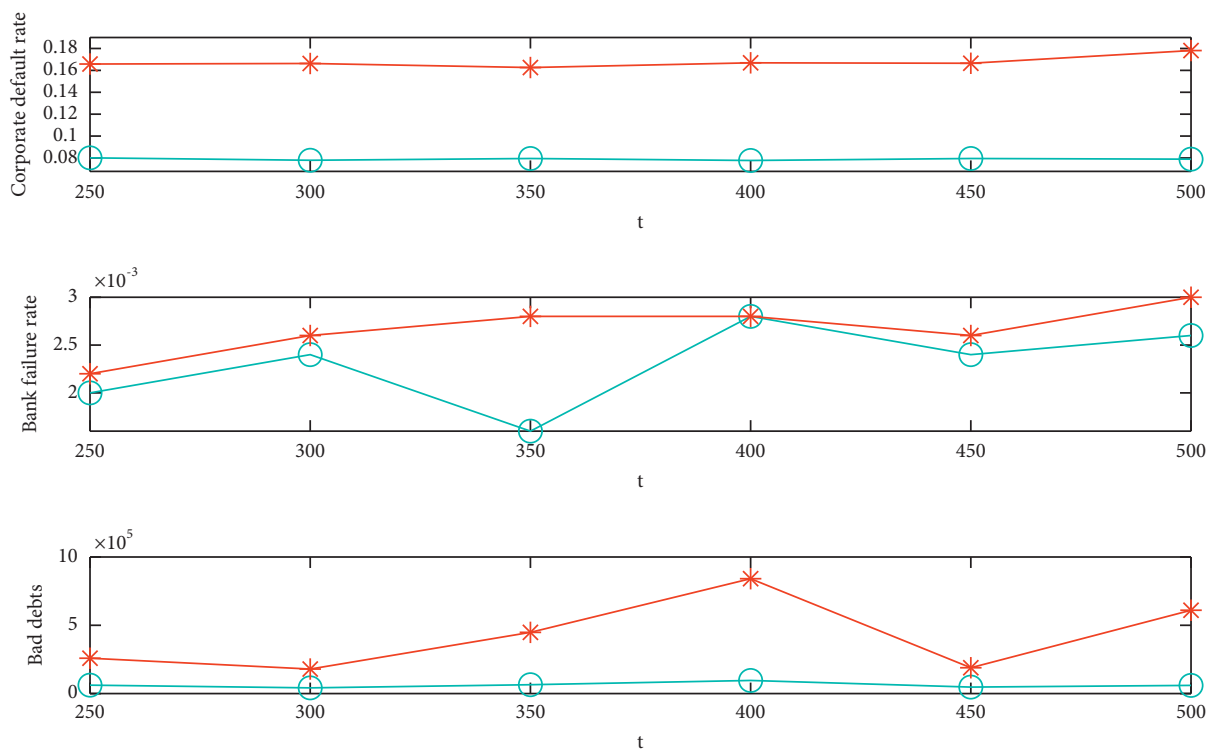

Figure 11: Consumer market shocks and the evolution of risk contagion between banks and enterprises.

3.2.4. Impact of Shocks to the Largest Asset Companies on Risk Contagion between Banks and Enterprises. Since the subprime crisis in 2007, regulators have focused on the regulation of "too big to fail" financial institutions. But for the corporate body "too big to fail" is also a regulatory focus. Therefore, this paper analyzes the impact of external risk shocks to the largest asset companies on the entire banking network through computer simulation (as shown in Figure 12). It is assumed that the external risk shock of the enterprise with the largest assets is, respectively, implemented in $t=250, t=300, t=350, t=400, t=450$, and $t=500$ periods. Figure 12 illustrates the evolutionary path of firm default rates, bank insolvency rates, and the number of bad debts following external shocks to asset-max firms in each period, where the solid asterisk line represents the evolutionary path of the corresponding variable after a shock to the bank with the largest assets. The solid circle line represents the evolutionary path of each variable before the shock. From Figure 12, it can be seen that the default rate of firms per period is slightly higher than the default rate of firms per period before the shock. And bank insolvency rates are significantly higher than preshock bank insolvency rates. At the same time, for the whole network of banks and enterprises, the external shock of enterprises with the largest assets leads to a significant increase in the number of bad debts in each period, which intensifies the systemic risk of banks and enterprises. This is due to the default bankruptcy of the largest asset companies, which has led to a spike in the number of bad debts due to the size of their assets, causing banks to be unable to fully absorb 

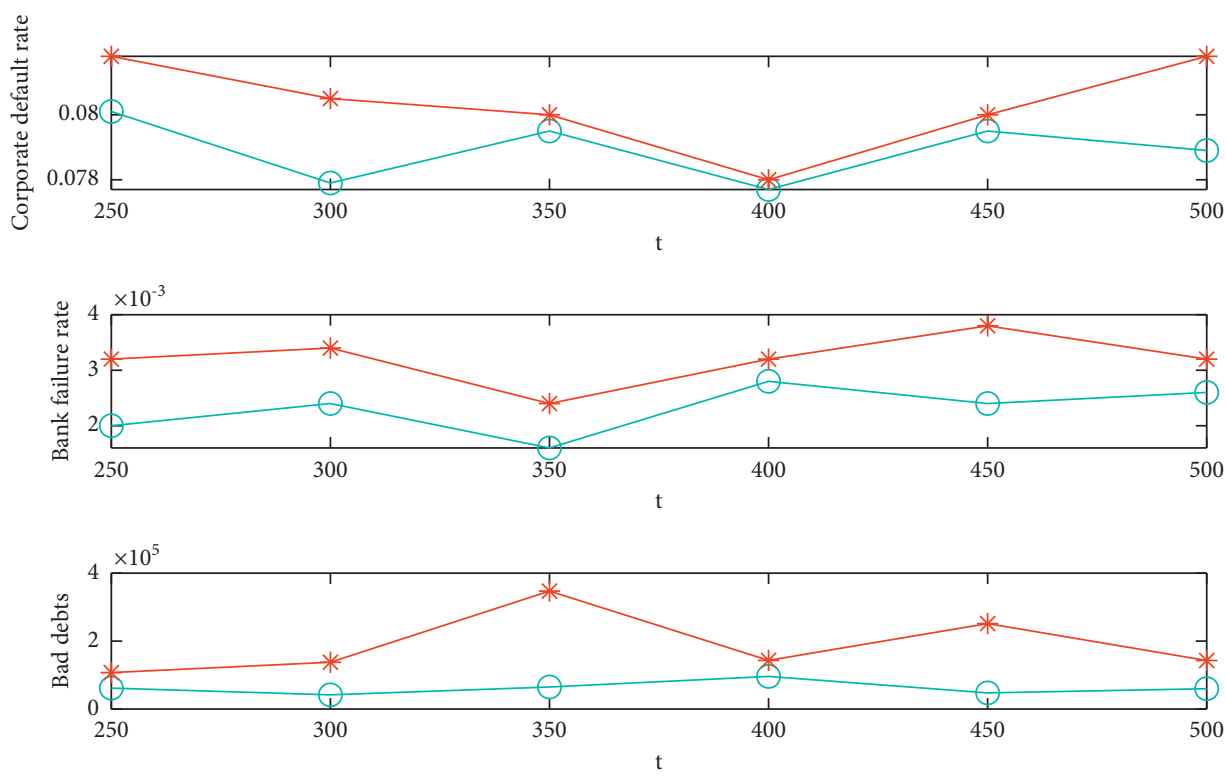

FIGURE 12: Shocks to the largest asset firms and the evolution of risk contagion between banks and enterprises.

the negative shock, making bank failures significantly higher. As a result, external shocks to the largest capital firms exacerbate the degree of risk contagion between banks and firms. This means that the regulator should do the supervision of financial institutions that are "too big to fail" and enterprises that are "too big to fail" to prevent the contagion of banking risks caused by their bankruptcy.

\section{Conclusion}

Considering the heterogeneity of interaction behaviors in the credit matching between banks and enterprises, in this paper, we construct an endogenous credit matching association network model that includes firms and banks. It also introduces production, decision-making, and learning mechanisms to portray the behavior and interaction rules of the two types of economic agents. The network evolution and its influencing factors of bank and enterprise credit risk contagion are explored. Based on the above study, we further consider the impact of various types of shocks on the evolution of risk contagion between banks and enterprises and conduct computational simulation analysis to substantially expand the existing study. The results of the study showed that the macroeconomic business cycle of the bank and enterprise system is the result of the interaction of bank and enterprise subjects under complicated financial conditions. The behavior rules, learning mechanism, and interaction of banks and firms lead to the heterogeneity of firms and their asset scale obeys the power-law distribution. The bank node degree distribution has a double power-law feature. The risk contagion between banks and enterprises is exacerbated by shocks to the largest banks with the largest assets, shocks to the largest banks with the largest revenues, shocks to the consumer market, and shocks to the largest enterprises with the largest assets. Banks play the role of financial stabilizers.
Based on the results of the study, the practical implications of this paper's research are that, in actual supervision, one cannot focus only on financial institutions with larger assets. Shocks to financial institutions with greater access, sharp fluctuations in the consumer market, and shocks to enterprises with larger assets can still bring about nonnegligible chain risks, which can spread through the banking and enterprises credit network. Therefore, in the daily supervision, a full range of supervisory policies should be formulated to effectively prevent the negative chain reaction that various shocks may bring to the entire banking system.

\section{Data Availability}

The method in this article is computer mathematical simulation. Numerical simulation analysis is the most effective way to test real-time dynamic data without a large number of empirical validations. The authors consider the heterogeneity of behavioral rules, learning rules, and interaction rules and construct a bank-firm credit matching network model based on ABM (agent-based model) model and reinforcement learning algorithm to analyze the interaction behavior and credit risk network contagion mechanism by using Matlab2016b software. This paper does not have the data that can be obtained because they directly use the plot function of Matlab2016b software to make the images.

\section{Conflicts of Interest}

The authors declare that they have no conflicts of interest.

\section{Acknowledgments}

The authors wish to express their gratitude to the referees for their invaluable comments. This work was supported by the National Natural Science Foundation of China (no. 
71871115), the Major Project of Philosophy and Social Science Research in Colleges and Universities in Jiangsu Province (no. 2019SJZDA035), and Young and Middle-Aged Academic Leaders of Qinglan Project in Jiangsu Province.

\section{References}

[1] I. Giulia, J. Saqib, and G. P. Francisco, "Systemic risk on the interbank market," Journal of Economic Behavior \& Organization, vol. 61, no. 4, pp. 525-542, 2006.

[2] S. Li, "Contagion risk in an evolviong network model of banking systems," Advances in Complex Systems, vol. 14, no. 5, pp. 673-690, 2011.

[3] A. Krause and S. Giansante, "Interbank lending and the spread of bank failures: a network model of systemic risk," Journal of Economic Behavior \& Organization, vol. 83, no. 3, pp. 583-608, 2012.

[4] T. Lux, "Emergence of a core-periphery structure in a simple dynamic model of the interbank market," Journal of Economic Dynamics and Control, vol. 52, pp. A11-A23, 2015.

[5] K. Anand, P. Gai, and M. Marsili, "Rollover risk, network structure and systemic financial crises," Journal of Economic Dynamics and Control, vol. 36, no. 8, pp. 1088-1100, 2012.

[6] B. Simone and G. Tedeschi, "From banks' strategies to financial (in) stability," International Review of Economics \& Finance, vol. 47, pp. 255-272, 2017.

[7] T. Chen, Q. Yang, and Y. Wang, "Double-layer network model of bank-enterprise counterparty credit risk contagion," Complexity, vol. 2020, Article ID 3690848, 25 pages, 2020.

[8] G. Tedeschi, A. Mazloumian, M. Gallegati, and D. Helbing, "Bankruptcy cascades in interbank markets," PLoS One, vol. 7, no. 12, Article ID e52749, 2012.

[9] T. Chen, J. He, and X. Li, "An evolving network model of credit risk contagion in the financial market," Technological and Economic Development of Economy, vol. 23, no. 1, pp. 22-37, 2017.

[10] S. Battiston, D. Delli Gatti, M. Gallegati, B. Greenwald, and J. E. Stiglitz, "Credit chains and bankruptcy propagation in production networks," Journal of Economic Dynamics and Control, vol. 31, no. 6, pp. 2061-2084, 2007.

[11] D. Barro and A. Basso, "Credit contagion in a network of firms with spatial interaction," European Journal of Operational Research, vol. 205, no. 2, pp. 459-468, 2010.

[12] T. Chen and S. Wang, "Incomplete information model of credit default of micro and small enterprises," International Journal of Finance \& Economics, pp. 1-19, 2021.

[13] Y. Hou, Y. Xiong, X. Wang, and X. Liang, "The effects of a trust mechanism on a dynamic supply chain network," Expert Systems with Applications, vol. 41, no. 6, pp. 3060-3068, 2014.

[14] L. Riccetti, A. Russo, and M. Gallegati, "Leveraged networkbased financial accelerator," Journal of Economic Dynamics and Control, vol. 37, no. 8, pp. 1626-1640, 2013.

[15] L. Bargigli, L. Riccetti, A. Russo, and M. Gallegati, "Network calibration and metamodeling of a financial accelerator agent based model," Journal of Economic Interaction and Coordination, vol. 15, no. 2, pp. 413-440, 2020.

[16] F. Giri, L. Riccetti, A. Russo, and M. Gallegati, "Monetary policy and large crises in a financial accelerator agent-based model," Journal of Economic Behavior \& Organization, vol. 157 , no. 157 , pp. $42-58,2019$.

[17] E. Catullo, M. Gallegati, and A. Palestrini, "Towards a credit network based early warning indicator for crises," Journal of Economic Dynamics and Control, vol. 50, no. 50, pp. 78-97, 2015.
[18] D. Delli Gatti, M. Gallegati, B. C. Greenwald, A. Russo, and J. E. Stiglitz, "Business fluctuations and bankruptcy avalanches in an evolving network economy," Journal of Economic Interaction and Coordination, vol. 4, no. 2, pp. 195-212, 2009.

[19] J. He, X. Sui, and S. Li, "An endogenous model of the credit network," Physica A: Statistical Mechanics and its Applications, vol. 441, pp. 1-14, 2016.

[20] T. Chen, Y. Wang, Q. Zeng, and J. Luo, "Network model of credit risk contagion in the interbank market by considering bank runs and the fire sale of external assets," Physica A: Statistical Mechanics and Its Applications, vol. 542, pp. 1-17, Article ID 123006, 2020.

[21] S. W. Li, L. Wang, and X. X. Liu, "Systemic risk across the banking sector and the firm sector," Systems Engineering-Theory \& Practice, vol. 40, no. 10, pp. 2492-2504, 2020.

[22] L. Tesfatsion, "Agent-based computational economics: a constructive approach to economic theory," Handbook of Computational Economics, vol. 2, pp. 831-880, 2006.

[23] C. Gauthier, A. Lehar, and M. Souissi, "Macroprudential capital requirements and systemic risk," Journal of Financial Intermediation, vol. 21, no. 4, pp. 2216-2228, 2012.

[24] S. Battiston, M. Puliga, R. Kaushik, P. Tasca, and G. Caldarelli, "DebtRank: too central to fail? Financial networks, the FED and systemic risk," Scientific Reports, vol. 2, no. 1, pp. 541$1-541-6,2012 \mathrm{a}$.

[25] R. Miranda and B. Tabak, Contagion Risk within Firm-Bank Bivariate Networks, Central Bank of Brazil, Research Department, Brasilia, Brazil, 2013.

[26] M. Braun and B. Larrain, "Finance and the business cycle: international, inter-industry evidence," The Journal of Finance, vol. 60, no. 3, pp. 1097-1128, 2005.

[27] C. Raddatz, "Liquidity needs and vulnerability to financial underdevelopment," Journal of Financial Economics, vol. 80, no. 3, pp. 677-722, 2006.

[28] Q. Ashraf, B. Gershman, and P. Howitt, "Banks, market organization, and macroeconomic performance: an agentbased computational analysis," Journal of Economic Behavior \& Organization, vol. 135, pp. 143-180, 2017. 